\title{
Relative influences of catchment- and reach-scale abiotic factors on freshwater fish communities in rivers of northeastern Mesoamerica
}

Esselman PC, Allan JD. Relative influences of catchment- and reach-scale abiotic factors on freshwater fish communities in rivers of northeastern Mesoamerica. Ecology of Freshwater Fish 2010: 19: 439-454. (C) 2010 John Wiley \& Sons A/S

Abstract - While the abiotic factors important to freshwater fish assemblages at a reach scale are well understood, studies of larger scale constraints have yielded variable conclusions, spurring a need for further studies in new biogeographic contexts. This study investigated the importance of catchment- and reach-scale abiotic factors to variation in freshwater fish assemblages in rivers of northeastern Mesoamerica. Abiotic variables and fish data from 72 sampling sites on main stem rivers of Belize were used with partial constrained ordination to determine the proportion of spatially structured and unstructured variation in fish presence and absence, relative abundance, and community metrics explained by catchment- and reach-scale environmental factors. Results showed that, combined, catchment and reach variables explained a large portion of the total variation in the fish assemblage data (54-75\%), and that catchment environment explained a greater portion of variation (42-63\%) than reach environment (34-50\%). Variables representing landscape position (local elevation, watershed area) and their reach-level correlates (channel width, depth variation, and substrate) correlated strongly to the fish assemblage data. Our results suggest that landscape-scale factors have a stronger relative influence on assemblages than environmental conditions at the reach scale within our study area. These results contrast with past findings that showed greater local scale influence in landscapes with low anthropogenic disturbance levels. Our findings suggest that biodiversity conservation efforts should consider assemblage variation across a longitudinal gradient, and that a multi-catchment region is a biologically relevant scale for fish conservation planning and coordination in northeastern Mesoamerica.

\section{P. C. Esselman', J. D. Allan²}

${ }^{1}$ Department of Fisheries and Wildlife, Michigan State University, East Lansing, MI, USA, ${ }^{2}$ School of Natural Resources and Environment, University of Michigan, Ann Arbor, MI, USA

Key words: habitat; scale; abiotic factors; cichlids; Belize

P. C. Esselman, Department of Fisheries and Wildlife, Michigan State University, 13 Natural Resources Building, East Lansing, MI 488241222, USA; e-mail: pce@msu.edu

Accepted for publication April 21, 2010

\section{Introduction}

Ecologists have long sought to identify factors that regulate patterns in local community composition and structure through space and time. An emergent perspective from this pursuit is that local diversity is often the result of a nested hierarchy of abiotic constraints that spans multiple spatio-temporal scales (Allen \& Starr 1982; Schluter \& Ricklefs 1993). In stream and river ecosystems, numerous authors have postulated that assemblages at fine scales within a river reach are structured relative to local abiotic factors that are, in turn, constrained at the larger scales of the valley segment or catchment (Frissell et al. 1986; Townsend 1996; Poff 1997). A number of studies have substantiated this concept by demonstrating the influences that abiotic factors at multiple scales have on finer scale abiotic factors and freshwater taxa across biogeographic contexts (e.g., Johnson et al. 2007). Much work also points to the overriding influence of landscape modification by humans on habitat and organisms at every scale (reviewed in 


\section{Esselman \& Allan}

Allan 2004). Still, the majority of studies of organismenvironment relationships have focused at small spatio-temporal extents that limit our ability to discern large-scale controls (Dunham \& Rieman 1999; Fausch et al. 2002; Durance et al. 2006), and create a mismatch between the scale of ecological knowledge and the scales at which management interventions must occur to protect and restore ecosystem integrity (Wiens 2002; Lake et al. 2007). For these reasons, studies that characterise community variation across relevant spatial scales should help to advance a more generalised understanding of aquatic community regulation, and can be an important prerequisite to aquatic conservation efforts (Angermeier \& Winston 1999).

Past studies of freshwater fishes in streams and rivers have led to a generalised understanding of abiotic correlates to variation in fish assemblages. At the reach scale, local channel structure and hydraulic conditions have been linked to fish community attributes in temperate and tropical streams (Gorman \& Karr 1978; Schlosser 1982; Statzner et al. 1988; Angermeier \& Schlosser 1989; Angermeier \& Winston 1998). Studies in disparate geographies show relatively consistent patterns of assemblage variation along longitudinal gradients of increasing stream order. Though there are exceptions, studies show an increase in fish species richness downstream (Horowitz 1978; Schlosser 1982), with faunal changes that may be gradual or abrupt in nature and tend to coincide with changes in physical habitat (reviewed by Matthews 1998). While there is clear evidence of the importance of local habitat and landscape position on fishes, evidence of possible direct or indirect constraints placed on local assemblages by factors at larger scales has been less thoroughly researched.

Prior studies have yielded interesting yet highly variable findings that can help with the formation of hypotheses in unstudied landscapes. Local assemblage variation often corresponds strongly to variation in landscape characteristics (Angermeier \& Winston 1999), particularly in landscapes with high degrees of land conversion to anthropogenic uses (Roth et al. 1996; Allan et al. 1997; Wang et al. 2003). Segmentand reach-scale factors have been found to relate strongly to biotic patterns, in isolation from and in relation to factors at the larger scale of the segment, catchment, or biogeographic region (Wang et al. 2003; Johnson et al. 2007). Consistent with nested hierarchy theory, a number of works indicate that site-specific environmental conditions and biota are dependent upon regional- or watershed-scale characteristics (e.g., Brazner et al. 2005) and that abiotic factors combined across nested spatial scales often explain a high portion of variation in fish assemblage patterns $(\sim 40$ 70\%; Wang et al. 2003; Johnson et al. 2007; StewartKoster et al. 2007). Finally, several works suggest that landscape factors often have less explanatory power than reach-scale variables (Lyons 1996; Lammert \& Allan 1999; Wang et al. 2003; Johnson et al. 2007), except in situations where landscapes are heavily dominated by anthropogenic land cover types. In human-dominated landscapes, conditions at the catchment scale have been shown to be of greater importance than local and riparian environmental conditions for stream fishes (Roth et al. 1996; Allan et al. 1997).

Multi-scale studies of freshwater fish assemblages are virtually nonexistent in watersheds of tropical Mesoamerica, but provide opportunities for testing the generality of nested hierarchy concepts. As in temperate regions, stream fish assemblages of Mesoamerica have been shown to be structured in part by local habitat conditions (Bussing \& Lopez 1977; Gorman \& Karr 1978; Winemiller 1983; Angermeier \& Schlosser 1989), and assemblages also vary predictably across longitudinal gradients (Angermeier \& Karr 1983; Lyons \& Schneider 1990; Winemiller \& Leslie 1992; Rodiles-Hernandez et al. 1999; Esselman et al. 2006). The only two studies conducted to date in northeastern Mesoamerica indicate the potential importance of distance from the sea, temperature, and salinity (Schmitter-Soto \& Gamboa-Perez 1996), and the influence that surface geology may have on site-level physicochemistry and fish assemblage structure (Esselman et al. 2006). Yet, virtually nothing has been published that examines the influences of abiotic factors across multiple spatial scales on Mesoamerican fish assemblages.

The present study investigates the relative importance of catchment- and reach-scale abiotic factors to variation in fish assemblage composition in streams and rivers of northeastern Mesoamerica. For the purposes of this study, catchment-scale factors are defined as those that measure integrated conditions in the landscape upstream of a given sampling location (e.g., proportion of different geologies in the watershed upstream of a location), or the position of a location within the landscape (e.g., distance from the river mouth). In contrast, reach-scale factors describe local habitat conditions (e.g., channel morphology, substrates, fish cover, etc.) in 300-1300 m sections of the river channel that encompass multiple riffle/run/pool sequences in streams and small rivers, or several river bends in larger river habitats that are free of runs and riffles.

Based on the findings from prior studies reviewed above and our knowledge of the study area, we explored three principal explanations about the nature of multi-scale abiotic influences on freshwater fishes in a relatively little-impacted landscape in northeastern Mesoamerica. We predicted that: (i) reach-scale abiotic conditions would account for more assemblage 
variation than catchment conditions, because of relatively low levels of landscape conversion to human uses; (ii) environmental conditions and the fish community would have a shared spatial structure driven by large scale gradients in geology, climate, and topography; and (iii) catchment longitudinal position would correlate strongly to compositional and community variation, both directly and indirectly, via influences on local habitat conditions. Although our a priori expectation was that each of these predictions would be supported, the descriptive and comparative value of a study of multi-scale controls on fish communities in a novel geography compelled the investigation. To examine our predictions, we partitioned the proportion of spatially structured and unstructured variation in fish community data explained by catchment- and reachscale environmental factors, and identified the abiotic variables with the highest influence on community patterns at both scales.

\section{Material and methods}

\section{Study area and sample sites}

Our investigation was carried out in the domestic and international waters that drain to the coast of Belize, including portions of southern Mexico and northeastern Guatemala. Sixteen major drainage basins and numerous small coastal drainages are contained within this $45,750 \mathrm{~km}^{2}$ area (Fig. 1). Basins vary in size, traverse a variety of geologic types and topographies, and drain a diversity of land cover types (Lee et al. 1995; Esselman \& Boles 2001). Twelve of the 16 major rivers are high-gradient, low $\mathrm{pH}$ streams that originate in the metamorphic and volcanic rocks of the Maya Mountains (Fig. 1), then flow through landscapes dominated by limestone and sedimentary rock before entering the coastal plain and discharging into the shelf lagoon that separates the coast from the Mesoamerican Barrier Reef. The northernmost rivers originate in karst hills, drain the low relief limestone platform of the Yucatan Peninsula, and discharge into Chetumal Bay, which in turn connects to the shelf lagoon. The three southernmost rivers begin in Guatemala and flow eastward to the Gulf of Honduras. In addition to flowing waters, the study area has an abundance of fresh and brackish water lagoons and wetlands that include swamp forests, herbaceous marshes, and open water areas, often in association with riverine habitats (Esselman \& Boles 2001).

Daily mean temperatures are warm throughout the year, ranging from a low of $16{ }^{\circ} \mathrm{C}$ in the winter to a high of $33{ }^{\circ} \mathrm{C}$ in summer months (Hartshorn et al. 1984). A strong north-to-south precipitation gradient exists, with the northern portion of the study area receiving approximately $1000 \mathrm{~mm}$ of rain annually and the southern portion receiving up to $4000 \mathrm{~mm}$ (Wilson 1980). The timing of precipitation is seasonal, with a dry season lasting from January to May and a wet season from June to November. The area is highly prone to hurricanes in the late summer and early fall (Wilson 1980).

Miller (1966) called northern Mesoamerica a 'strong center of evolution' for fishes, because of its many endemic genera and species. The area is particularly rich in poeciliids ( $>34$ species) and cichlids (>44 species) (Miller 1966; Bussing 1976), and contains at least 130 species of freshwater fishes in 34 genera and 10 families (Bussing 1976), a number that rises to over 200 species when predominately marine fishes that inhabit fresh waters are included (Miller 1966). One hundred and twenty-six fish species have been reported from the catchments of the study area (Schmitter-Soto \& Gamboa-Perez 1996; Greenfield \& Thomerson 1997; Schmitter-Soto 1998; Esselman et al. 2006).

Seventy-two sampling sites were selected on the main stems of 3rd through 6th order rivers in 12 of the major catchments in the study area (Fig. 1). Fifty-three of these sites were identified by locating a random start point within the first $5000 \mathrm{~m}$ of habitat upstream from the river mouth, then placing a site each 20 river $\mathrm{km}$ along the main stem channels and major tributaries. These sites were sampled for fishes and habitat during base flow conditions in 2006 and 2007. An additional 19 sites were used from a dataset assembled in 2000 (Esselman et al. 2006). These sites were selected randomly within physiographic strata representing distinct combinations of stream size, gradient, and underlying geology within one basin in the southern part of the study area (Monkey River; Fig. 1).

\section{Fish sampling}

Fishes were collected using backpack and boat electrofishing during base-flow conditions in the dry season months between January and May. The goal at any given site was to capture as many species as possible in all habitats present. In wadeable rivers with riffle-run-pool morphology, reach lengths were 39 times the mean stream width, and a single electrofishing pass was performed through all available habitats using a Smith-Root $12 \mathrm{~B}^{\circledR}$ battery powered backpack electrofisher (Smith-Root, Inc., Vancouver, WA, USA). In riffles, fishes were shocked downstream into a $2 \mathrm{~m} \times 5 \mathrm{~m}$ seine (5-mm mesh) blocking the channel, while in runs and shallow pools, samples were collected by shocking and dip-netting fishes near cover, from areas free of cover, and from within the water column. All captured fishes were placed in five gallon buckets with aerators, and processed frequently to avoid stress. Slight distinctions existed in the fishing 


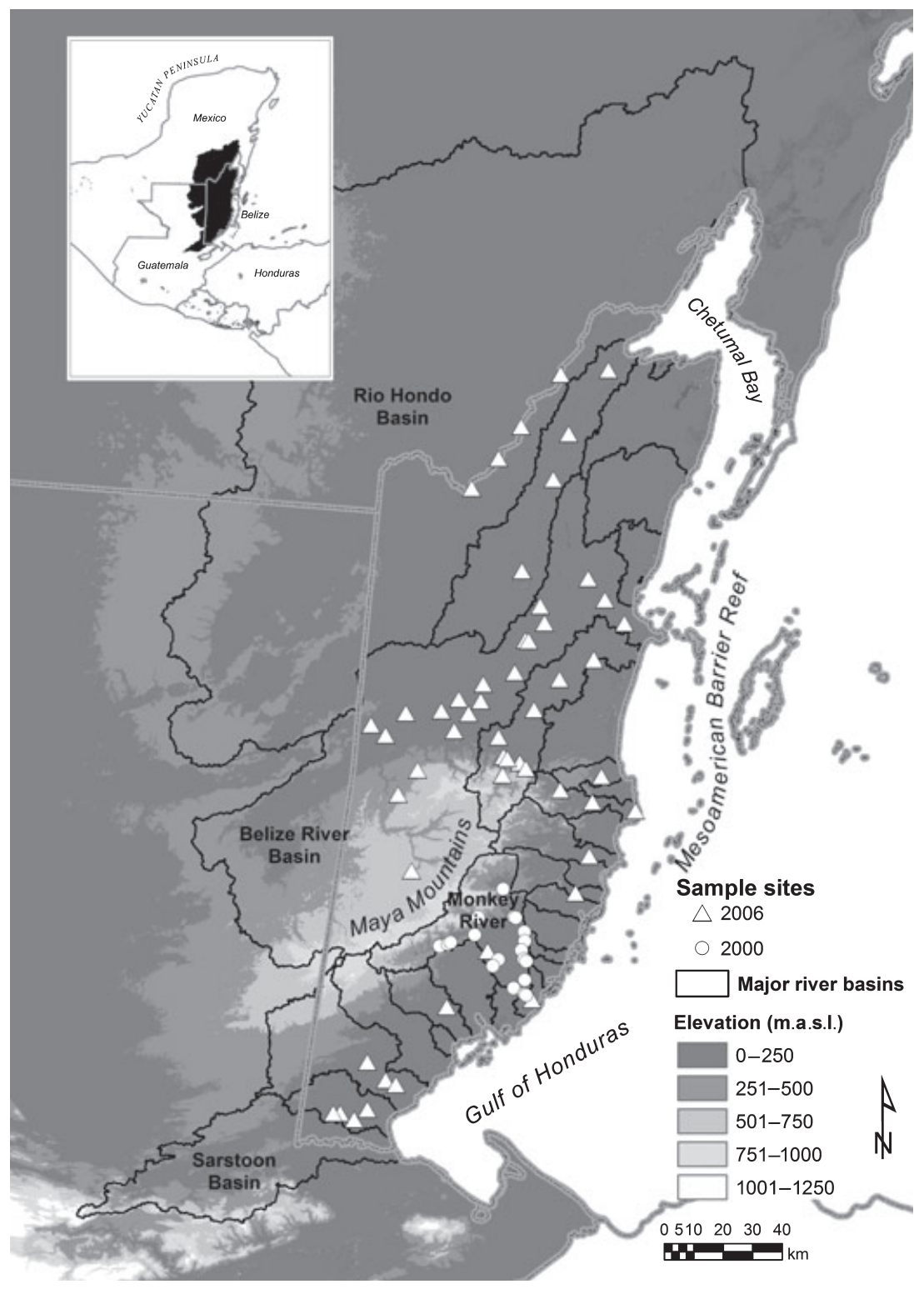

Fig. 1. Study area showing elevation, major drainage basins, important geographic features, and locations of all sampling sites. Sampling locations in the Monkey River from 2000 are identified with a white circle, while those sampled in 2006-2007 are marked by a white triangle. approaches used between the electrofishing conducted in 2006-2007 and that done in 2000 in the Monkey River. In the Monkey River, backpack electrofishing was used to sample both coastal plain and mountain sites, whereas all coastal plain sites were sampled by boat electrofishing in 2006-2007 (including three sites in the Monkey River basin). Additionally, the coastal plain samples in the 2000 Monkey River study were collected during the moonless portion of the night to capture more taxa, and deep pools in the coastal plain were also fished by angling and trotlines to add species for the presence/absence analysis.

Boat electrofishing was conducted at 38 of the 72 sampling sites (Fig. 1) using a Smith-Root GPP 5.0 generator-powered electrofisher deployed from booms on an aluminium boat in reaches that were uniformly $1300 \mathrm{~m}$ in length. Within this reach, a single pass was made along one bank, and fishes were placed in an aerated live-well. A single boat electrofishing pass generally involved no less than 3000 s of shocking time.

Most fishes captured were identified to species in the field using the dichotomous key of Greenfield \& Thomerson (1997), and released after positive identification. Individuals with uncertain identifications or for which meristic counts or microscope diagnostics were necessary were euthanized and preserved in $10 \%$ formalin for later examination. Voucher collections for the 2000 study were deposited at the Georgia Museum of Natural History (Athens, GA, USA), and for 20062007 at University of Michigan Museum of Zoology (Ann Arbor, MI, USA). Given that we only sampled during dry season conditions using a single electrofishing pass at each site, our sample represents a snapshot of dry season fish assemblages, and is not 
considered an exhaustive census of all species present at a given site across seasons.

\section{Reach and riparian environmental variables}

At each site where we fished, information was collected about channel morphology, substrates, fish cover, bank conditions, riparian width, and riparian land cover. Methods differed slightly between wadeable and nonwadeable sites. In wadeable sites, thirteen transects separated by a distance equal to three times the mean stream width were established at each site. At each transect, wetted width, water depth, fish cover type and extent, and habitat type (riffle, run, pool) were determined. Depth and dominant substrate type were recorded at five equidistant points across each transect. Fish cover types were assigned a categorical value from 0 to 4 according to the percentage of a 10 -m wide zone centred on each transect line occupied by each cover type $(0=$ cover type absent, $1=0-10 \%$ covered, $2=10-40 \%, 3=40-75 \%, 4=75 \%$; after Lazorchak et al., 1998). The area of bottom covered by large woody debris $(>0.30 \mathrm{~m}$ diameter) in the river channel was estimated and normalised based on reach length to calculate $\mathrm{m}^{2} \cdot 100 \mathrm{~m}^{-1}$ of channel. Electric conductivity, $\mathrm{pH}$, and water temperature were measured once at each site using hand-held water quality meters manufactured by Hanna Instruments ${ }^{\circledR}$ (Woonsocket, RI, USA). At each transect, bank stability was categorically estimated according to the percentage of bank composed of unconsolidated bare soil $(0-25 \%$; $25-50 \% ; 50-75 \%$, or $75-100 \%$ ). Riparian forest width and extent of different land uses were also estimated at each transect within $15 \mathrm{~m}$ from the top of the bank away from the river channel.

At nonwadeable sites, 10 transects were established at intervals of $130 \mathrm{~m}$ along the river channel. Channel dimensions, substrates, habitat types, large woody debris, water quality, bank stability, and riparian width and cover were assessed in the same manner as wadeable sites. Fish cover was assessed using the same categories as above within a $4 \mathrm{~m}$ by $10 \mathrm{~m}$ zone along each bank centred on the transect line.

\section{Catchment environmental variables}

To capture landscape-level variation in catchments upand downstream of each sampling site, we assembled a geospatial database that consisted of 25 variables representing site location and landscape position, climate, surficial geology, land use, upstream road density in catchment, and distance to nearest human settlement (Table 1). The cumulative upstream influence of different variables was represented using the weighted flow accumulation tool in the spatial analyst extension of ArcGIS 9. $2^{\circledR}$ (ESRI Corp., Redlands, CA,
USA). Weighted flow accumulation performs a downstream summation of pixel numeric values within a grid of equally sized cells, drawing on a flow direction grid to infer downstream directionality. This is in contrast to raw flow accumulation - the count of all pixels upstream of a given pixel in a map grid. To calculate proportional variables (e.g., upstream proportion of a geology class), binary grids showing the presence or absence of each geological class were created and used as the weight grid in the flow accumulation process, and then divided by raw flow accumulation to yield a representation of the proportion of the catchment in a given feature class. Mean upstream values of continuous variables were calculated by the same process, except that we used continuous (e.g., mean annual temperature) instead of binary values in the weight grid.

Surficial geology of the study area consists of five different classes. The Maya Mountains (Fig. 1) are composed of variably metamorphosed argillaceous and arenaceous sediments dated from the Pennsylvanian period, with local intrusions of granite, and some extrusive volcanic rocks. Surrounding the Maya Mountains, and composing much of the northern part of the country, are Cretaceous and early Tertiary limestones, dolomites, and breccias (called Cretaceous limestone in Table 1). To the south of the Maya Mountains, underlying the southernmost six drainage basins, is a distinctive series of shales, turbidites, sandstones, conglomerates, and mudstones of late Cretaceous and early Tertiary age, known as the Toledo Formation. In the late Tertiary, layers of marls, limestone, and gypsum were deposited in several areas north of the Maya Mountains on the Yucatan Platform (called Tertiary sedimentary in Table 1). Finally, much of the coastal plain is covered by Quaternary alluvium from river terraces, sand bars, and calcareous sand and mud (called Quaternary alluvium in Table 1).

\section{Data analysis}

Prior to analysis, we summarised our datasets (Tables 1 and 2). For each site, we averaged measures taken across all transects to calculate the following metrics: means of width, depth, fish cover rating, riparian width, and bank stability; coefficient of variation for depths; percent composition of habitat types, substrates, fish cover types, and riparian land uses; Shannon diversity of fish cover and substrate types; and sum of the area of stream bottom covered by large woody debris divided by 0.01 times the reach length for each site. For our fish data, we summarised the numeric abundance of each species at each site, and calculated the following site-level community metrics: richness, Shannon diversity index, percent top carnivore individuals and species, percent migratory 


\section{Esselman \& Allan}

Table 1. Mean, SE and range of values for each catchment and reach variable.

\begin{tabular}{|c|c|c|c|c|c|c|}
\hline Variable & Description & Mean + SE & Range & PA & ABUN & COMM \\
\hline \multicolumn{7}{|c|}{ Watershed location and landscape } \\
\hline distsea & Distance downstream to sea $(\mathrm{km})$ & $89 \pm 10$ & $1-367$ & $x$ & $x$ & $x$ \\
\hline area_shed & Upstream watershed area $\left(\mathrm{km}^{2}\right)$ & $1647 \pm 319$ & 0-9813 & $x$ & $x$ & $x$ \\
\hline elev_shed & Average catchment elevation (masl) & $306 \pm 19$ & $6-720$ & $\mathrm{x}$ & $\mathrm{x}$ & $\mathrm{X}$ \\
\hline elev_loc & Local elevation (masl) & $59 \pm 11$ & $2-468$ & $x$ & $x$ & $x$ \\
\hline slope_loc & Local slope (degrees) & $4.1 \pm 0.6$ & $0-26$ & & & \\
\hline temp_shed & Average annual air temp in catchment $\left({ }^{\circ} \mathrm{C}\right)$ & $23 \pm 0$ & $21-26$ & $x$ & $x$ & \\
\hline prec_shed & Average annual rainfall in catchment (mm) & $2050 \pm 63$ & $1260-3747$ & $x$ & $x$ & $x$ \\
\hline \multicolumn{7}{|c|}{ Watershed surficial geology and soils } \\
\hline alluv & $\%$ Quaternary alluvium & $12 \pm 2$ & $0-100$ & & & \\
\hline limestn & $\%$ Cretaceous limestone & $35 \pm 3$ & $0-100$ & & $\mathrm{X}$ & $\mathrm{X}$ \\
\hline sedim & $\%$ Tertiary sedimentary & $3 \pm 1$ & $0-72$ & & & \\
\hline toledo & $\%$ Toledo formation & $3 \pm 1$ & $0-53$ & $x$ & $x$ & $x$ \\
\hline \multicolumn{7}{|c|}{ Watershed land use and human influence } \\
\hline agric & $\%$ Agriculture land use & $18 \pm 2$ & $0-100$ & $\mathrm{x}$ & & $\mathrm{x}$ \\
\hline urban & $\%$ Urban land use & $0.49 \pm 0.28$ & $0-16$ & $\mathrm{X}$ & & $\mathrm{X}$ \\
\hline forest & $\%$ Forest land use & $74 \pm 2$ & $0-100$ & $\mathrm{X}$ & $\mathrm{X}$ & \\
\hline savanna & $\%$ Savanna & $1 \pm 0.28$ & $0-13$ & $\mathrm{X}$ & & \\
\hline wetland & $\%$ Wetland & $0.41 \pm 0.16$ & $0-7$ & $\mathrm{X}$ & & \\
\hline snear_dist & Linear distance to nearest human settlement (km) & $4312 \pm 477$ & $468-26,196$ & $\mathrm{X}$ & & $\mathrm{X}$ \\
\hline roadprop & Percent of pixels in catchment with roads present & $0.84 \pm 0.1$ & $0-4$ & & & \\
\hline \multicolumn{7}{|c|}{ Reach channel morphology } \\
\hline wetwidt & Mean wetted width $(\mathrm{m})$ & $28 \pm 2$ & $2-67$ & $\mathrm{x}$ & $\mathrm{X}$ & $\mathrm{x}$ \\
\hline depcovar & Coefficient of variation of water depth (m) & $77 \pm 3$ & $32-149$ & $\mathrm{x}$ & & $\mathrm{x}$ \\
\hline wdratio & Ratio of width to depth (ratio) & $34 \pm 2$ & $7-103$ & & & \\
\hline pool & $\%$ Stream reach that is pool & $63 \pm 4$ & $0-100$ & & $\mathrm{X}$ & $\mathrm{X}$ \\
\hline \multicolumn{7}{|c|}{ Reach substrate } \\
\hline bedrck & $\%$ Bedrock substrate in reach & $7 \pm 2$ & $0-56$ & & & \\
\hline boulder & $\%$ Boulder substrate in reach & $5 \pm 1$ & $0-33$ & $\mathrm{x}$ & $\mathrm{x}$ & $\mathrm{X}$ \\
\hline cobble & $\%$ Cobble substrate in reach & $14 \pm 2$ & $0-68$ & & $\mathrm{x}$ & $\mathrm{X}$ \\
\hline gravel & $\%$ Gravel substrate in reach & $13 \pm 2$ & $0-55$ & & & \\
\hline sand & $\%$ Sand in reach & $23 \pm 3$ & $0-91$ & $\mathrm{x}$ & $\mathrm{X}$ & \\
\hline clay & $\%$ Clay in reach & $6 \pm 2$ & $0-80$ & $\mathrm{x}$ & $\mathrm{x}$ & $\mathrm{X}$ \\
\hline H'sub & Shannon diversity of substrates & $0.79 \pm 0.05$ & $0-1.67$ & & $\mathrm{X}$ & \\
\hline \multicolumn{7}{|c|}{ - } \\
\hline logs & Logs $>0.30 \mathrm{~m}$ diameter and $>1 \mathrm{~m}$ long (number $100 \cdot \mathrm{m}^{-1}$ ) & $8 \pm 1$ & $0-29$ & & & $\mathrm{X}$ \\
\hline sumfcov & Mean fish cover (index) & $35 \pm 2$ & $7-105$ & & & \\
\hline H'cover & Shannon diversity of fish cover types & $1 \pm 0$ & $0-2$ & & & \\
\hline \multicolumn{7}{|c|}{ Stream bank condition } \\
\hline bnkstab & Mean bank stability rating (index) & $1.30 \pm 0.04$ & $1.00-2.23$ & $\mathrm{x}$ & & \\
\hline \multicolumn{7}{|c|}{ Reach water quality and temperature } \\
\hline cond & Conductivity $\left(\mu \mathrm{Sm} \cdot \mathrm{cm}^{-2}\right)$ & $437 \pm 66$ & $22-2531$ & $\mathrm{x}$ & & $\mathrm{x}$ \\
\hline $\mathrm{pH}$ & $\mathrm{pH}$ & $7 \pm 0$ & $6-9$ & $\mathrm{X}$ & $\mathrm{X}$ & \\
\hline temp & Water temperature $\left({ }^{\circ} \mathrm{C}\right)$ & $27 \pm 0$ & $21-33$ & $\mathrm{X}$ & $\mathrm{X}$ & $\mathrm{X}$ \\
\hline \multicolumn{7}{|c|}{ Riparian land uses } \\
\hline ripwidth & Width of forested buffer (up to $16 \mathrm{~m}$ from stream) & $12 \pm 0$ & $1-16$ & $\mathrm{X}$ & $\mathrm{x}$ & $\mathrm{x}$ \\
\hline ripforest & $\%$ Forested within $16 \mathrm{~m}$ of bank & $66 \pm 4$ & $8-100$ & & $\mathrm{X}$ & \\
\hline ripdisturb & $\%$ Disturbed vegetation types (human or natural) within $16 \mathrm{~m}$ of bank & $23 \pm 3$ & $0-92$ & $\mathrm{X}$ & & \\
\hline riphuman & $\%$ Human cover types (agriculture and other within $16 \mathrm{~m}$ of bank & $9 \pm 2$ & $0-85$ & & & \\
\hline ripagric & $\%$ Agriculture within $16 \mathrm{~m}$ of bank & $6 \pm 1$ & $0-54$ & & & \\
\hline
\end{tabular}

Variables that were retained in the analysis (marked with an $\mathrm{X})$ were significantly correlated $(P<0.05)$ with fish variables in CCAs between the two environment datasets and three fish datasets, which contained information on presence/absence (PA), relative abundance (ABUN), and community metrics (COMM).

individuals and species, percent narrowly endemic individuals and species, percent poeciliid individuals and species, and percent cichlid individuals and species. Narrow endemics were defined as those whose entire range occupies three or less of the freshwater ecoregions defined for Mesoamerica by
Abell et al. (2008). After summary, we organised three fish data matrices: species presence/absence, relative abundance by count, and community summary metrics.

We organised three separate matrices of explanatory variables: catchment, reach/riparian (heretofore 
Table 2. Species codes, names, class, number of sites recorded as present $(M)$, and mean relative abundance (proportion of all fish counted) of the 32 fish species used in the analysis.

\begin{tabular}{|c|c|c|c|c|c|}
\hline Code & Common name & Species name & Class & N & $\begin{array}{l}\text { Mean Rel. } \\
\text { Abun. }\end{array}$ \\
\hline Aaen & Central tetra & Astyanax aeneus & & 70 & 0.262 \\
\hline Bgua & Machaca & Brycon guatemalensis & & 23 & 0.041 \\
\hline Hcom & Mayan tetra & Hyphessobrycon compressus & & 41 & 0.057 \\
\hline Ifur & Blue catfish & Ictalurus furcatus & & 5 & 0.004 \\
\hline Rgua & Guatemalan chulin & Rhamdia guatemalensis & & 42 & 0.028 \\
\hline Rlat & Filespine chulin & Rhamdia laticauda & & 42 & 0.035 \\
\hline Rten & Dogtooth rivulid & Rivulus tenuis & & 1 & \\
\hline Bbel & Pike killifish & Belonesox belizanus & C & 53 & 0.011 \\
\hline Glum & Sleek mosquitofish & Gambusia luma & & 45 & 0.035 \\
\hline Gsex & Teardrop mosquitofish & Gambusia sexradiata & & 2 & \\
\hline Gyuc & Yucatan mosquitofish & Gambusia yucatana australis & & 1 & \\
\hline Hbim & Twospot livebearer & Heterandria bimaculata & & 38 & 0.072 \\
\hline Pmex & Shortfin molly & Poecilia mexicana & & 66 & 0.164 \\
\hline Ppet & Sailfin molly & Poecilia petenensis & & 6 & 0.024 \\
\hline Pter & Mountain molly & Poecilia teresae & $\mathrm{E}$ & 1 & \\
\hline Porr & Mangrove molly & Poecilia orri & & 1 & \\
\hline Pfai & Picotee livebearer & Phallichthys fairweatheri & & 1 & \\
\hline Xhel & Green swordtail & Xiphophorus helleri i & & 38 & 0.066 \\
\hline Xmac & Southern platyfish & Xiphophorus maculatus & & 2 & \\
\hline Asp1 & Belize silversides & Atherinella sp. 1 & & 40 & 0.03 \\
\hline Oaen & Obscure swamp eel & Ophisternon aenigmaticum & & 55 & 0.011 \\
\hline Pcro & Burro grunt & Pomadasys crocro & $\mathrm{C}, \mathrm{M}$ & 15 & 0.007 \\
\hline Arob & False firemouth cichlid & Amphilophus robertsoni & & 55 & 0.026 \\
\hline Cboc & Chisel-tooth cichlid & Cichlasoma bocourti & $\mathrm{E}$ & 5 & 0.017 \\
\hline Csal & Yellowbelly cichlid & Cichlasoma salvini & & 67 & 0.059 \\
\hline Curo & Mayan cichlid & Cichlasoma urophthalmus & C & 18 & 0.013 \\
\hline Cspi & Blue-eye cichlid & Cryptoheros chetumalensis & & 64 & 0.078 \\
\hline Onil & Nile tilapia & Oreochromis niloticus & & 10 & 0.011 \\
\hline Pfri & Yellowjacket cichlid & Parachromis friedrichsthalii & C & 12 & 0.006 \\
\hline Pspl & Bay snook & Petenia splendida & C & 34 & 0.014 \\
\hline Roct & Jack Dempsey & Rocio octofasciata & & 19 & 0.012 \\
\hline Taur & Golden firemouth cichlid & Thorichthys aureus & $\mathrm{E}$ & 7 & 0.1 \\
\hline Tmee & Firemouth cichlid & Thorichthys meeki & & 42 & 0.128 \\
\hline Vint & Northern checkmark cichlid & Vieja intermedia & & 9 & 0.037 \\
\hline Vgod & Southern checkmark cichlid & Vieja godmanni & $\mathrm{E}$ & 4 & \\
\hline Vmac & Blackbelt cichlid & Vieja maculicauda & & 27 & 0.061 \\
\hline Vsyn & Redhead cichlid & Vieja synspila & & 34 & 0.076 \\
\hline Amon & Mountain mullet & Agonostomus monticola & $M$ & 22 & 0.043 \\
\hline Jpic & Hog mullet & Joturus pichardi & $M$ & 4 & \\
\hline Gdor & Bigmouth sleeper & Gobiomorus dormitor & & 44 & 0.023 \\
\hline Aban & Green river goby & Awaous banana & $\mathrm{M}$ & 23 & 0.012 \\
\hline
\end{tabular}

Species with less than five observations were considered rare and were only used to calculate community metrics, but not included in the relative abundance matrix. Class refers to whether or not a species is a carnivore with a trophic level greater than $4(\mathrm{C})$, a sub-regional endemic $(\mathrm{E})$, or migratory $(\mathrm{M})$. Class designations were used to calculate community metrics. referred to as reach variables), and spatial structure. Riparian variables were combined with reach variables because there were very few $(N=5)$, and they were measured in the field at the reach scale (vs. in a broader longitudinal and lateral sense using remote sensing data, e.g., Lammert \& Allan (1999)). The matrix of spatial variables included all of the terms in a cubic trend surface regression with latitude $(y)$ and longitude $(x)$ (terms included were $x, y, x^{2}, x y, y^{2}, x^{3}$, $x^{2} y, x y^{2}$, and $y^{3}$; see Legendre 1990; Borcard et al. 1992). Inclusion of these terms ensures representation not only of linear gradients in species data, but also more complex features like patches and gaps (Borcard et al. 1992).
For our analysis, we used a variance decomposition technique known as partial constrained ordination (Borcard et al. 1992), which uses canonical correspondence analysis (CCA) or redundancy analysis (RDA) to determine the unique effect of groups of explanatory variables on community composition. Constrained ordination is a multivariate approach that constrains species data by linear combinations of environmental variables (ter Braak \& Prentice 1988), and allows for easy interpretation of relationships between environmental factors and whole assemblage composition or structure. RDA is the constrained ordination approach used to describe species that respond linearly to environmental gradients. CCA is 


\section{Esselman \& Allan}

the equivalent procedure for species data that exhibit unimodal responses to gradients. Partial CCA and RDA are a posteriori techniques that partition variation in species datasets into individual components that describe pure and shared influences of sets of predictor data (Borcard et al. 1992; Anderson \& Gribble 1998). Here we partitioned the variation in fish presence-absence, relative abundance, and community data sets that were explained by our environmental and spatial datasets.

The analysis had two steps using CCA and/or RDA: (i) data reduction and (ii) variance partitioning. We ran three processes to reduce the master catchment and reach datasets to a smaller number of variables with a low degree of collinearity. In the first process, we calculated pair-wise Pearson correlation coefficients for each combination of predictors in the catchment and reach datasets independently. We identified variable pairs with Pearson correlation coefficients greater than 0.65 , and retained one of the two variables in each pair that we felt was the better predictor of fish assemblages. Next, we ran detrended correspondence analysis (DCA) to determine the appropriate constrained ordination technique (CCA or RDA) to use in our analyses. The gradient length of species composition along the first DCA axis allows for an estimation of whether the species responses to the environmental data are likely to be linear or unimodal. Data with greater than 2 SD of turnover along the first DCA axis are likely to respond unimodally and should be used with CCA, while data with less than $2 \mathrm{SD}$ of turnover on that axis are likely to respond linearly to environmental gradients and should be used with RDA (ter Braak 1995). Each of the three fish datasets had greater than $2 \mathrm{SD}$ of turnover on the first DCA axis, so CCA was determined as the appropriate technique in each case. The final step in data reduction was to run CCA for each explanatory dataset paired with each of the three fish datasets using the stepwise forward selection procedure in Canoco $^{\odot}$ (v.4.02 for Windows, GLW-CPRO, Wageningen, The Netherlands), which uses a Monte-Carlo permutation test to identify variables that are significantly related to response matrices (ter Braak 1992). One thousand permutations were run using and variables were judged as significant at $P \leq 0.05$.

Canonical correspondence analysis was used to estimate the variation in assemblage characteristics explained by catchment (CAT), reach (REA), and spatial variables (SPAT). We used the approach of Anderson and Gribble (1998) to partition total variation of each fish data set into components that were explained by catchment, reach, and spatial predictors. This involves twelve CCA runs to determine the sum of canonical eigenvalues of each explanatory dataset alone, and with covariation attributable to one or both of the other explanatory matrices partialled out of the analysis. The twelve runs were as follows ([run number] constraining variables(covariables)): [1] CAT; [2] REA; [3] SPAT; [4] CAT(REA); [5] CAT(SPAT); [6] CAT (REA + SPAT); [7] REA (CAT); [8] REA(SPAT); [9] REA(CAT + SPAT); [10] SPAT(CAT); [11] SPAT(REA); [12] SPAT(CA$\mathrm{T}+\mathrm{REA})$. To determine the percent of variation explained by each constrained or partial ordination, the sum of canonical eigenvalues for each run is divided by the sum of all eigenvalues obtained by an unconstrained correspondence analysis (CA) of the species data and multiplied by 100 . The sum of all eigenvalues obtained by CA is a measure of the total variation for each fish data matrix (Borcard et al. 1992).

For each of the three fish datasets, two bi-plots were created to display correlations between the locations of species or community metrics and environmental and spatial variables from the catchment and reach datasets. Correlations between environmental factors and species or community metrics were inferred from visual interpretation of plots, with specific attention to the direction and length of environmental vectors in relation to species or community measures. Longer environmental vectors in the plots were interpreted as having a stronger correlation with the species or community points found on the same axis as that vector.

\section{Results}

\section{Fish characteristics}

Sampling sites occurred across a range of abiotic conditions (Table 1), and sites ranged widely in terms of their positions on main stem rivers within mostly forested landscapes. Fish assemblages sampled at these sites were reflective of the biogeographic context and the fact that the rivers of the study area are connected directly to the sea. A total of 74 fish species and 24,590 individuals were collected at 72 sites. Thirty-five of the species were from marine families that can tolerate full seawater but also use fresh water (Miller 1966). An additional 11 rare species occurred at less than five sites and were included in the calculation of community summary metrics only. After removal of rare species and species from marine families (except diadromous fishes that live in fresh water as adults), 32 species remained (Table 2), which were used in the analysis of environmental influences on fish presence-absence and relative abundances. Within this group, 11 families were represented, with Cichlidae (13 spp.), Poecillidae (six spp.) and Characidae (three spp.) being the most diverse. Two species exhibited clear numerical dominance: the central tetra (Astyanax aeneus; mean relative abundance $=0.26$ ), 
and the shortfin molly (Poecilia mexicana; mean relative abundance $=0.16$ ). Across all sites combined, cichlids had the highest mean relative richness and relative abundance $(36 \%$ and $31 \%$ of species and individuals, respectively) followed by poediliids ( $25 \%$ and $27 \%$ of species and individuals, respectively). Top carnivores, migratory fishes, and endemics generally comprised low proportions of species and individuals captured at a site. Species richness (with nonmigratory marine families excluded) ranged from two at high elevation sites to 22 in large coastal plain rivers, with an average of 15 species per site. The high relative richness of cichlids and livebearers is consistent with the biogeographic context of northeastern Mesoamerica (Miller 1966).

\section{Variable selection}

Variables were selected for inclusion in the analysis using (i) inter-correlated strengths, and (ii) forward stepwise CCA after removal of strongly intercorrelated variables. Reduction of inter-correlated abiotic factors eliminated five variables from the catchment dataset (distance to ridge, local precipitation, slope in catchment, local temperature, and \% volcanic rock in catchment), and four variables from the reach dataset (average depth, \% silt substrates, \% run habitat, \% riffle habitat). After correlation reduction, but prior to variable reduction with CCA, there were 18 variables in the catchment dataset, and 23 in the reach dataset. Stepwise CCA identified the catchment, reach, and spatial variables that related significantly to the ordinated fish data sets. Based on significant correlations with the three fish datasets, 14 (of 18) catchment variables were retained for further examination of the fish presence-absence data, nine for relative abundance dataset, and 10 for the community characteristic dataset (Table 1). In the reach variable reduction process, 11 (of 23) variables were retained for the fish presence-absence dataset, 11 for the abundance dataset, and 10 for the community characteristics dataset (Table 1). In the spatial variable reduction, seven of the nine terms were retained for the analysis of presence-absence data $\left(x, y, x^{2}, x y, y^{2}, x y^{2}\right.$, and $\left.y^{3}\right)$, all nine were retained for the abundance analysis, and five were retained for the analysis of community characteristics $\left(x, y, x y, x^{2} y\right.$, and $\left.y^{3}\right)$.

\section{Ability of environmental and spatial variables to explain fish assemblage variation}

Relative to our predictions we were interested in relative magnitudes of variation explained by catchment versus reach environmental variables, and also in the variation shared between the two scales, which can help us assess how strongly catchment factors may be influencing reach factors and biota. Using constrained and partial CCA, we evaluated: the percent variation explained by catchment and reach datasets with no partialling of covariation (runs [1] and [2]), the percent variation explained uniquely by catchment and reach datasets with covariation of the other scale partialled out (runs [4] and [7]), shared variation that could be explained by either environmental dataset ([1]-[4]), and total variation explained by both scales added together $([1]+[7])$. We found that the catchment dataset explained about $25 \%$ more variation in the fish datasets than reach data (Fig. 2). When the influence of the other scale was partialled out for catchment and reach datasets, the unique influence of catchment variables accounted for roughly double the amount of variation in fish datasets explained uniquely by the reach environmental variables (Fig. 2). The variation shared by catchment and reach scale variables was substantial $(30 \%, 22 \%$, and $38 \%$ of variation in the presence-absence, abundance, and community data sets, respectively), suggesting that fish are at least partially correlated with the same catchment gradients that appears to be structuring the reach scale variables. Taken together, unique and shared variation explained by catchment and reach environmental variables explained a relatively large portion of the total variation in the fish assemblage matrices- $62 \%$, $54 \%$, and $76 \%$ for the presence-absence, abundance, and community data sets respectively (Fig. 2).

To examine our second prediction that environmental conditions and the fish community would have a shared spatial structure, we used our spatial data matrix to compare spatially structured environmental variation in the fish matrices with nonspatial environmental variation and spatial community variation not explained

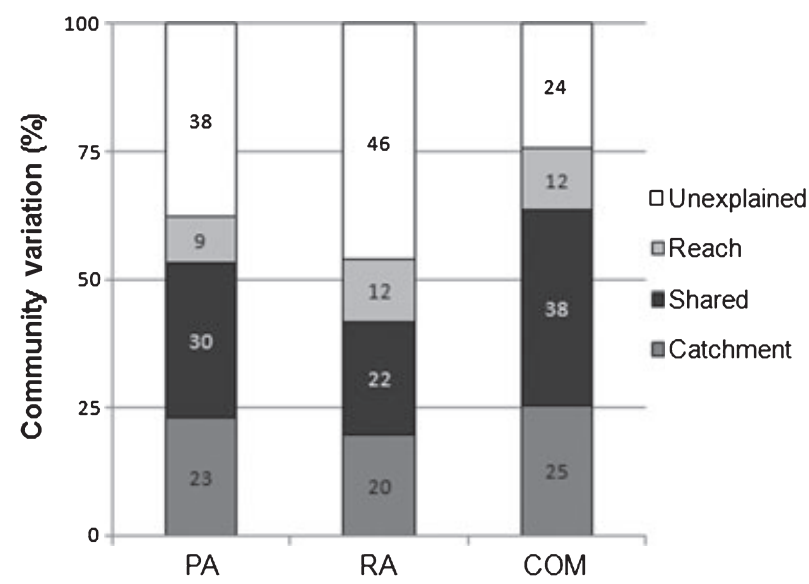

Fig. 2. The percentage of total variation explained by different scales of environmental data for fish presence-absence (PA), relative abundance (RA), and community measures $(\mathrm{COM})$ using partial CCA. 'Shared' represents variation that can be explained by either the catchment or reach datasets. 


\section{Esselman \& Allan}

by the environmental datasets. Spatially structured environmental variation is the portion of variation shared commonly by environmental and spatial datasets ([1-5] for CAT, [2-8] for REA, [1] + [2] - [5] - [9] [12] for CAT + REA). Nonspatial environmental variation ([5] for CAT, [8] for REA, [5] + [9] for CAT + REA) is the unique variation explained by catchment and reach factors with spatial terms partialled out. A greater portion of the variation explained by environmental variables was spatially-structured than nonspatial when examined at the catchment scale (average 30\% vs. $20 \%$ across the three fish dataset) and the reach scale (24\% vs. $17 \%)$. When both scales were combined, the difference between spatial and nonspatial environmental variation was more equivalent (34\% vs. $30 \%$; Fig. 3 right). The absolute magnitudes of nonspatial environmental variation in the fish data, though smaller than the spatial portion, suggest a nontrivial influence from variables with no discernable spatial pattern. Spatial community variation is the portion of spatial variation that could not be described by catchment or reach variables ([10] for CAT, [11] for REA, and [12] for CAT + REA). Relatively small amounts of spatial community variation were present after partitioning out catchment influence $(11 \%, 16 \%$, and $6 \%$ for the presence-absence, abundance, and community data sets) and catchment and reach together $(10 \%, 13 \%, 5 \%)$. However, the portion of spatial community variation not explained by reach factors was much larger $(20 \%, 21 \%, 17 \%$; Fig. 3 middle).

\section{Relations between environmental variables and fish assemblages}

An examination of bi-plots from the CCA runs with the reduced environmental datasets and the fish datasets revealed a number of interrelationships between species and community metrics and environmental factors at the catchment and reach scales
(Figs 4 to 6). For the presence-absence dataset, at least three species-environment associations were evident. The first association was between the south-
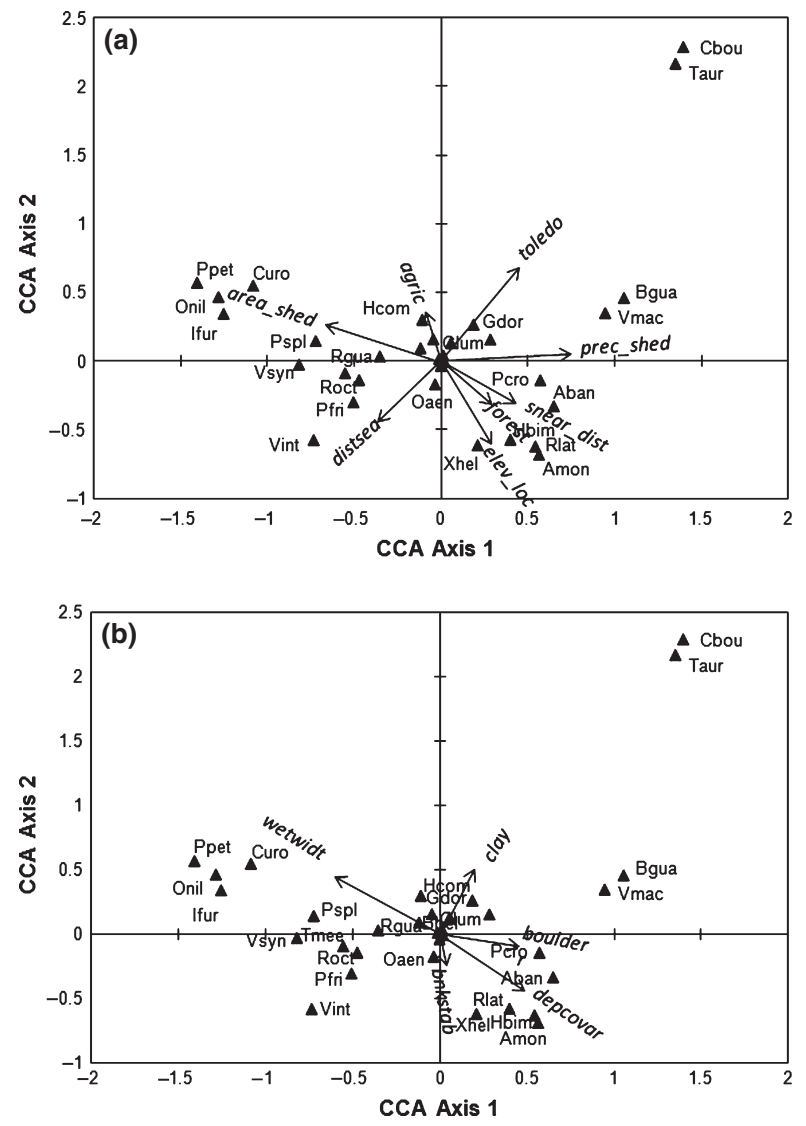

Fig. 4. CCA bi-plot of species with catchment-scale environmental influences (a) and reach influences (b) based on presence or absence data. Triangles indicate fish species labelled with species codes from Table 2. Arrows indicate the direction of increasing values of the environmental variables, and the length of arrows indicates the degree of correlation of the variable with community data. Note that only vectors for the strongest environmental correlates are shown to aid interpretation.

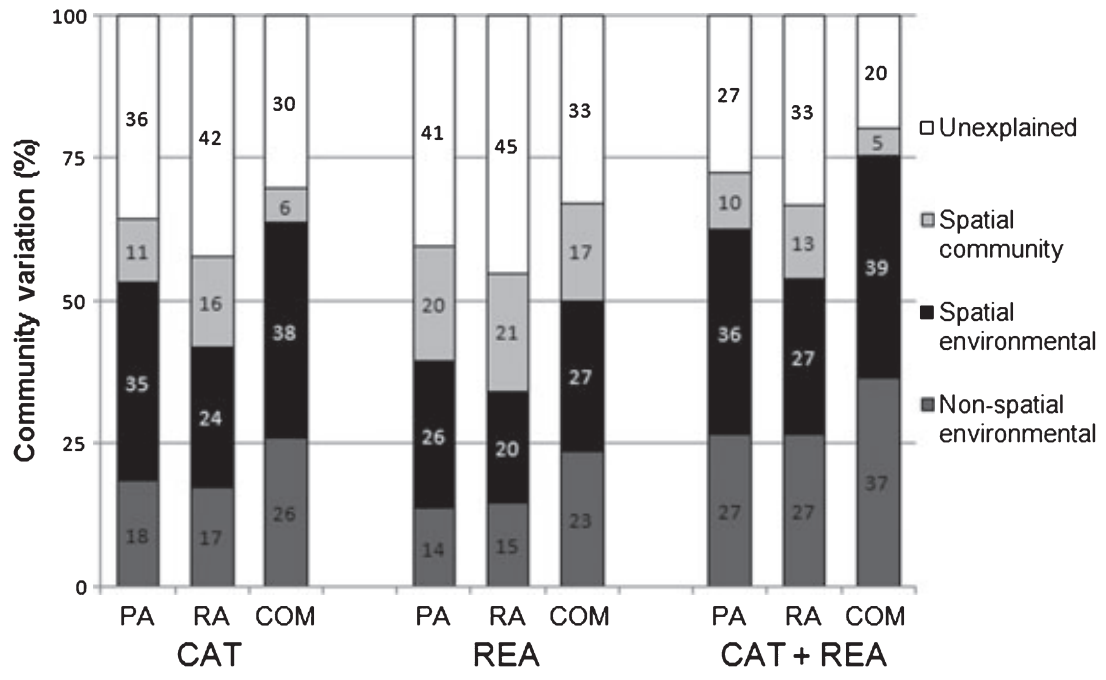

Fig. 3. The percentage of total variation in presence absence (PA), relative abundance (RA), and community (COM) datasets explained by partitioned spatial community, spatially environmental, and nonspatial environmental catchment variables (CAT, left), reach variables (REA, middle), and catchment plus reach variables (CAT + REA, right). Numbers inside each bar represent percent variation explained. 
ern endemic chisel-tooth cichlid (Cichlasoma boucourti) and golden firemouth cichlid (Thorichthys aureus), increasing catchment percentage of Toledo Formation rock, and decreasing distance from sea (Fig. 4a, upper left). The Toledo Formation is the geologic type that underlies the southernmost six catchments in the study area, and thus corresponds to the species distributions of those fishes limited to the south. At the reach level (Fig. 4b) these species were weakly correlated to increasing percent clay substrate. The second association was a strong correlation between decreasing catchment rainfall and species that occurred in the northern and southern parts of the study area, respectively. As mentioned in the description of the study area, precipitation increases from higher to lower latitudes across the study area. Species on the high rainfall/low latitude end of this gradient included the machaca (Brycon guatemalensis) and the blackbelt cichlid (Vieja maculicauda) (Fig. 4a, right side). The low rainfall/high latitude end of this gradient correlated to the presence of the redhead cichlid (Vieja synspila), Jack Dempsey cichlid (Rocio octofasciata), and the Guatemalan chulin (Rhamdia guatemalensis). In the same direction as the low rainfall/high latitude group, but in stronger association with watershed area, was a group of fishes captured frequently in the large lowland rivers of northern Belize, such as the Mayan cichlid (Cichlasoma urophthalmus), Peten molly (Poecilia petenensis), blue catfish (Ictalurus furcatus), and Nile tilapia (Oreochromis niloticus) (Fig. 4a, upper left side). At the reach scale, this high latitude/large watershed group correlated to channel characteristics typical of rivers with larger watersheds - greater channel widths and decreased percent boulder substrates (Fig. 4b, upper left). A third association was apparent between mountain river species, including the mountain mullet (Agonostomus monticola), twospot livebearer (Heterandria bimaculata), filespine chulin (Rhamdia latic$a u d a$ ), and green swordtail (Xiphophorus helleri i), and increasing local elevation (Fig. 4a, bottom left). At the reach scale the mountain group correlated strongly to increasing variation in depths and decreasing channel widths (Fig. 4b). In sum, patterns in species presence-absence were most strongly tied to a latitudinal precipitation gradient, watershed area, and elevation, with reach associations to channel size, depth diversity, and substrates.

The relative abundance bi-plots reinforced the importance of catchment variables representing landscape position (distance from sea, local elevation), watershed size, and reach variables representing river size and substrate as drivers or proxies for the drivers of community composition. As in the presenceabsence data, the percent of Toledo Formation geology correlated to the southern endemic cichlids, and also to the blackbelt cichlid ( $V$. maculicauda) and machaca (B. guatemalensis), which are found in greatest abundances in the southern part of the study area (Fig. 5a, top left). Both the blackbelt cichlid and the machaca are widely distributed in Central America south to Panama, but fall out of the northern Belize fauna potentially as a result of habitat changes created by the disappearance of mountainous topography, or in the case of the blackbelt cichlid, because of competition with congeneric species like the redhead cichlid (V. synspilum) that are highly successful in the Yucatan Platform rivers. Again, relationships between this group and reach variables were weak or absent. A second association was evident between several species and decreasing local elevation and distance from sea (Fig. 5, center left). These include the false firemouth cichlid (Amphilophus robertsoni) and the obscure swamp eel (Ophisternon aenigmaticum). At the reach level, these species were correlated positively with river width and $\mathrm{pH}$, and negatively with the percent forest in the riparian zone (Fig. 5b). The association between large river habitats and northern lowland river fishes was evident in the abundance data (Fig. 5a, bottom), as was also apparent
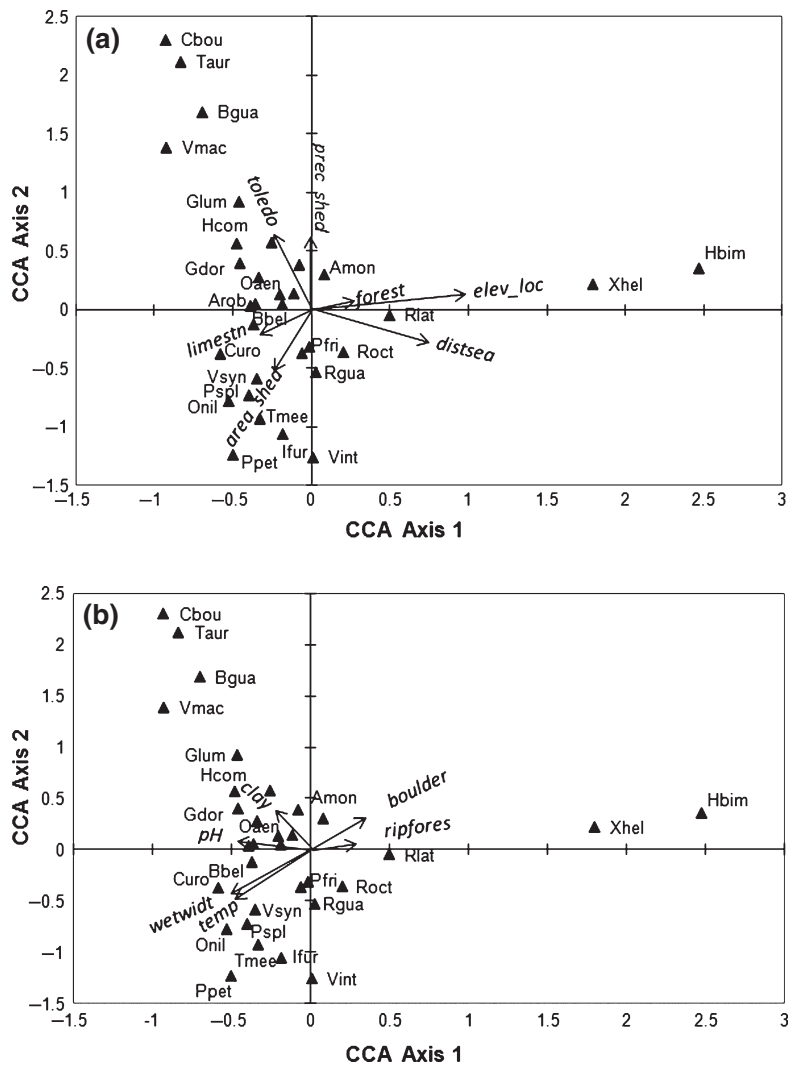

Fig. 5. CCA bi-plot of species with catchment-scale environmental influences (a) and reach influences (b) based on relative abundance data. Note that only vectors for the strongest environmental correlates are shown to aid interpretation. 


\section{Esselman \& Allan}

in the presence-absence bi-plot. At the reach-level increasing temperature and wetted width were associated with northern lowland river fishes. Finally, the only two species that are commonly found in the constrained and hydraulically stressful conditions in high elevation streams - the green swordtail ( $X$. helleri $i$ ) and twospot livebearer (H. bimaculata) were correlated strongly to increasing local elevation, with a weaker correlation to increasing riparian forest and decreasing wetted width at the local scale.

Community metrics were correlated to a more balanced mix of catchment and reach factors that included geology, local elevation, and watershed area at the catchment scale, and, at the reach level, channel morphology and substrates. In the bi-plot of community metrics with environment (Fig. 6), the southern endemic species were again linked to Toledo Formation geology with a weaker relationship to clay substrates at the reach scale. Poeciliid relative richness and abundance were strongly correlated to increasing local elevation, decreasing percent pool habitat, and decreasing channel width. Migratory species were
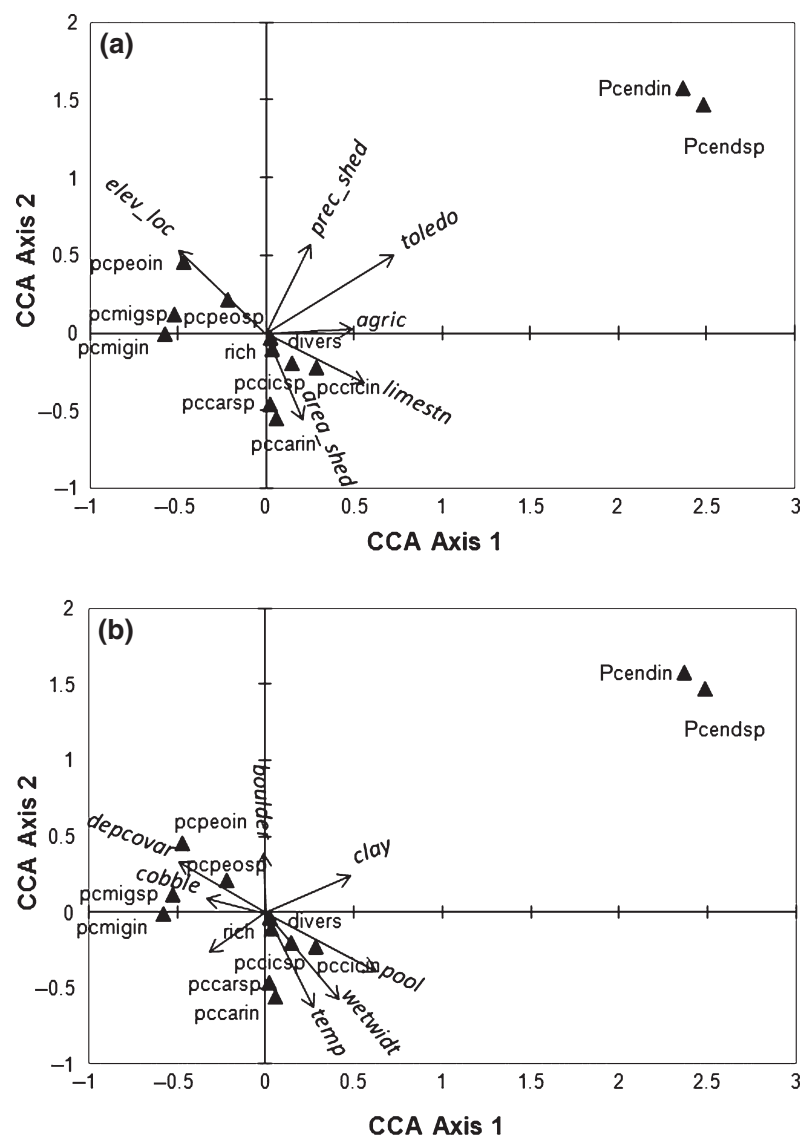

Fig. 6. CCA bi-plot of community metrics with catchment-scale environmental influences (a) and reach influences (b). Note that only vectors for the strongest environmental correlates are shown to aid interpretation. correlated to decreasing percentages of limestone, increasing depth variability, and decreasing percentages of clay substrates. This reflects the preference of most of the migratory species for the high gradient rivers of the Maya Mountains, away from the Cretaceous limestone deposits of the north and the foothills. Carnivore relative abundances and richness were linked most strongly to increasing watershed area and decreased percentages of boulder habitats, indicating that abundances of top predators (e.g., pike killifish, bay snook, yellowjacket cichlid) were greatest in larger river habitats. Cichlid species were linked to increasing percent Cretaceous limestone, decreasing local elevation, and, at the local level, to increasing wetted width and percent pool habitats. This reflects a preference by cichlids for larger coastal plain habitats, where they are primarily found below 100 masl (Bussing 1998). Finally, species richness and diversity were correlated with decreasing local elevation and increasing wetted width.

\section{Discussion}

Our results affirmed the existence of strong and weak multi-scale relationships between environmental conditions and fish assemblages in the small neo-tropical rivers of northeastern Mesoamerica. The first prediction, that reach-scale abiotic conditions should account for more assemblage variation than catchment conditions because of relatively low levels of human landscape domination, was not well supported by the results. Contrary to expectations, catchment scale environmental factors consistently accounted for more variation than reach variables (Fig. 2). Three explanations may account for this contradiction of findings from other settings. First, the study area spans strongly varying geologic, climatic, and physiographic types defined by the transition from the northern Yucatan Platform to the wetter Maya Mountains and Toledo Formation in the south. This environmental heterogeneity may have been more strongly reflected in the catchment-level dataset, as reflected in the greater portion of spatially structured variation in the community datasets accounted for by catchment factors over reach factors (Fig. 3). Second, the study area spans several biogeographic regions with characteristic species in northern Yucatan Platform rivers, the rivers of the Maya Mountains, and in the rivers draining the Toledo Formation. The inclusion of river basins from different biogeographic regions is likely to result in a greater explanatory importance of catchment environment, because catchment variables such as geology can place strong limits on species dispersal, colonisation and population persistence (Brown \& Lomolino 1998) as may be the case along the geologic contact zone of the Yucatan Platform and the Maya 
Mountains. By contrast, the faunal distinctiveness of the rivers draining the Toledo Formation may be more reflective of historical tectonic and river capture events associated with a major fault zone (the PolochicMotagua Fault) than current environmental conditions (Ornelas-García et al. 2008). Such historical drivers of current faunal patterns in the south may confound the apparent relationship between the Toledo Formation, its reach-scale correlates, and the southern fauna. A third possible explanation for the greater amount of variation explained by catchment scale factors may relate to the presence of a large number of marine fishes in the assemblage (35 species). Though these species were dropped from this analysis of freshwater fishes, they may still exert a strong influence on the freshwater community via competition and/or predation. Because most of these fishes occur in the near shore river reaches above the estuary (Esselman et al. 2006), there is a strong positional dimension to their presence, and also presumably to the influence that they may exert. Further analyses within more biogeographically or physiographically homogeneous regions or that incorporate the presence of marine predators as covariables could lead to conclusions more typical of past studies with greater relative amounts of variation described by reach factors.

The second prediction, that environmental conditions and the fish community would have a shared spatial structure driven by large scale gradients in geology, climate, and topography was moderately well supported by our results. Spatially structured environmental variation accounted for the greatest portion of variation in our community datasets (Fig. 3). This means that the community and environmental data have a fairly similar spatial structure that may indicate the same response to common underlying causes. Bi-plots can suggest what these causes or their proxies may be. For instance, precipitation showed repeated associations with environmental variables, species groups, and community metrics (such as the northern and southern species groups in Figs 4 and 5). Variables linked to watershed position and their reach level correlates have a consistent spatial pattern of east-west variation in the study area and were strong correlates to species patterns. However, despite indications of a common spatial structure between environmental factors and the fish community, from $14 \%$ to $37 \%$ of variation explained by environmental variables was nonspatial. This variation is likely to involve local effects of environmental variables on the fish community that have no spatial pattern that could be assessed by the cubic trend surface (Borcard et al. 1992). An additional 6-21\% of variation was spatially structured community variation that may have been caused by unmeasured environmental factors, biotic factors, or recent disturbance events. That the spatial community variation was a small fraction of the overall variation explained in the ordination with catchment and reach covariance partialled out (Fig. 3, right) indicates that few fundamental spatial-structuring processes were missed in this analysis.

The third prediction, that longitudinal position in the catchment would explain a substantial portion of compositional and community variation, both directly and indirectly through interactions with local habitat conditions, was supported by our findings. Variables that represented longitudinal position in the catchment (watershed area, distance from sea, and local elevation) and their reach level correlates (wetted width, coarse substrates, depth variation) related strongly to fish assemblage patterns (Figs 4 to 6). Local elevation was particularly well correlated with all fish datasets, and consistently varied in the same direction in the bi-plots as channel width, substrate size, and depth variation. These findings are consistent with the idea that local biota are constrained by local habitats that are in turn constrained by factors at larger landscape scales (Poff 1997). Our findings are also consistent with several previous studies in small Mesoamerican coastal drainages. Winemiller \& Leslie (1992) showed predictable longitudinal variation across a freshwater-marine ecotone that correlated to reach conditions like habitat size and salinity, while other authors have shown an inverse relationship between richness and distance from sea (Lyons \& Schneider 1990; Rodiles-Hernandez et al. 1999; Esselman et al. 2006). The present study reinforces the importance of landscape position, which itself may serve as a proxy for the finer scale habitat correlates that exert direct influences on Mesoamerican fish assemblages.

The findings provide an interesting contrast with the few previous studies that evaluated multi-scale environmental influences on river fish assemblages using similar methods. In the present study, environmental conditions across scales (excluding spatial variables) explained $54-76 \%$ of the total variation in fish assemblage composition. Similar studies have reported 40-51\% (Wang et al. 2003), 48\% and 72\% (Johnson et al. 2007), and 64\% (Stewart-Koster et al. 2007). This indicates that abiotic controls may be especially influential on the fish assemblages of our study area. In contrast to the present study, other studies have found that landscape factors often have less explanatory power than reach scale variables (Lyons 1996; Lammert \& Allan 1999; Wang et al. 2003; Johnson et al. 2007), though it has also been observed that land-use in human-dominated landscapes can override the influence of local and riparian habitat on stream fishes (Roth et al. 1996; Allan et al. 1997). As mentioned above, the finding of stronger catchment influence may be due to biogeographic variation, the 


\section{Esselman \& Allan}

influence of species from marine families, or the strong north to south geographic heterogeneity of the study area. Alternatively, Wiley et al. (1997) showed that inadequate sampling in time or space can inflate estimates of spatial variation attributed to large scale spatial factors, introducing an alternative explanation that may be the result of our sampling design.

This study is notable for its lack of a signal of human influence on fish assemblages at catchment or riparian scales. Very few indicators of human activities on the landscape (e.g., percent urban land cover, Table 1) entered into the reduced datasets. Instead, the strong influence of catchment factors occurred in a setting with very low rates of forest conversion to agriculture, urban, or other human uses (Table 1). This finding contrasts with the suggestions of workers in other geographies that reach-scale environment has greater explanatory power until human activities greatly modify land cover patterns, at which point landscape-scale variables become more important (Wiens 2002; Wang et al. 2003). Here we have shown that in watersheds with relatively little land cover conversion, landscape-scale factors seem to have a stronger relative influence on assemblages than environmental conditions at the reach scale. This does not imply that reach-scale controls are weak. On the contrary, when considered in combination with the shared variation that they explained with catchment factors, reach scale factors accounted for between 34\% and $50 \%$ of the total variation in our fish datasets (Fig. 2). The moderate level of landscape disturbance in our study area, coupled with strong natural gradients, may explain the shared explanatory roles of reach and catchment-scale variables for the fish assemblage.

We have presented strong correlative evidence of nested environmental controls on fish assemblages of northeastern Mesoamerica. These results suggest the importance of landscape position as a large scale spatial control, followed by habitat size and substrate at the reach scale, with little obvious influence of riparian habitats. This work has several implications for aquatic conservation in the study area. The first is that these aquatic systems seem to be almost wholly structured relative to natural (vs. anthropogenic) gradients, suggesting that the fish communities of the area may still be relatively unimpaired. Second, results suggest the existence of a unique narrow endemic species assemblage in southern Belize that may result from a biogeographic history that is distinct from the rest of the study area. Taxonomic inventories in this poorly sampled area could lead to new species discoveries, and aquatic protection efforts are warranted to ensure persistence of large populations of these endemics. Finally, because landscape position may be an important large scale control, biodiversity protection efforts must consider how to maintain ecological integrity across a positional gradient from the mountains to the sea and account for north-tosouth species turnover. Finally, this works supports the idea that the catchment scale or larger is a biologically relevant scale at which to conduct fish conservation planning to guard the integrity of local habitat conditions and fish communities in northeastern Mesoamerica.

\section{Acknowledgements}

This work was funded by the Inter-American Biodiversity Information Network on a grant from the World Bank Development Grants Facility, the Belize Protected Areas Conservation Trust, the Rackham Graduate School at the University of Michigan (UM), the UM School of Natural Resources and Environment, the UM Office of the Vice President for Research, and Rogol Energy Consultants, LLC. This work would not have been possible without facilitation by the Belize Foundation for Research and Environmental Education, El Colegio de la Frontera Sur, The Guatemala Program of the Nature Conservancy, the Belize Fisheries Department (Beverly Wade, George Myvett, and Rigoberto Quintana), and the Belize Forest Department (Wilbur Sabido, Raul Chun). Special thanks are also due to Lizhu Wang, Rebecca Esselman, Vincent Abreu, Juan Jacobo Schmitter-Soto, Matt Cushing, Shannon Brines, Steve Schill, Emil Cherrington, Sandor Ricketts, Rennick Jackson, David Buck, Sonny Gabutt, Michael Issa, and Miles, Lars, and Irin Lish. We thank Bernard Hugueny and two anonymous reviewers for their helpful comments. All field data collected as part of this research was conducted under protocol \#09339 issued by the University of Michigan University Committee on the Use and Care of Animals.

\section{References}

Abell, R., Thieme, M., Revenga, C., Bryer, M.T., Kottelat, M., Bogutskaya, N., Coad, B., Mandrak, N., Contreras Balderas, S., Bussing, W.A., Stiassny, M.L.J., Skelton, P.H., Allen, G.R., Unmak, P., Naseka, A., Ng, R., Sindorf, N., Robertson, J., Armijo, E., Higgins, J.V., Heibel, T.J., Wikramanayake, E., Olson, D., Lopez, H.L., Reis, R.E., Lundberg, J.G., Sabaj Perez, M.H. \& Petry, P. 2008. Freshwater ecoregions of the world: a new map of biogeographic units for freshwater biodiversity conservation. BioScience 58: 403-414.

Allan, J.D. 2004. Landscapes and riverscapes: the influence of land use on stream ecosystems. Annual Review of Ecology Evolution and Systematics 35: 257-284.

Allan, J.D., Erickson, D.L. \& Fay, J. 1997. The influence of catchment land use on stream integrity across multiple spatial scales. Freshwater Biology 37: 149-161.

Allen, T.F.H. \& Starr, T.B. 1982. Hierarchy: perspectives for ecological complexity. Chicago, IL: University of Chicago Press.

Anderson, M.J. \& Gribble, N.A. 1998. Partitioning the variation among spatial, temporal and environmental components in a multivariate data set. Australian Journal of Ecology 23: 158-167. 
Angermeier, P.L. \& Karr, J.R. 1983. Fish communities along environmental gradients in a system of tropical streams. Environmental Biology of Fishes 9: 117-135.

Angermeier, P.L. \& Schlosser, I.J. 1989. Species-area relationships for stream fishes. Ecology 70: 1450-1462.

Angermeier, P.L. \& Winston, M.R. 1998. Local vs. regional influences on local diversity in stream fish communities of Virginia. Ecology 79: 911-927.

Angermeier, P.L. \& Winston, M.R. 1999. Characterizing fish community diversity across Virginia landscapes: prerequisite for conservation. Ecological Applications 9: 335-349.

Borcard, D., Legendre, P. \& Drapeau, P. 1992. Partialling out the spatial component of ecological variation. Ecology 73 : 1045-1055.

ter Braak, C.J.F. 1992. Permutation vs. bootstrap significance tests in multiple regression and ANOVA. In: Jöckel, K.H., Rothe, G. \& Sendler, W., eds. Bootstrapping and related techniques. Berlin: Springer-Verlag, pp. 79-85.

ter Braak, C.J.F. 1995. Ordination. In: Jongman, R.H.G., Ter Braak, C.J.F. \& van Tongeren, O.F.R., eds. Data analysis in community and landscape ecology. New York, NY: Cambridge University Press, pp. 91-173.

ter Braak, C.J.F. \& Prentice, I.C. 1988. A theory of gradient analysis. In: Begon, M., Fitter, A.H., Ford, E.D. \& MacFadyen, A., eds. Advances in ecological research. London: Academic Press, pp. 271-317.

Brazner, J.C., Tanner, D.K., Detenbeck, N.E., Batterman, S.L., Stark, S.L., Jagger, L.A. \& Snarski, V.M. 2005. Regional, watershed, and site-specific environmental influences on fish assemblage structure and function in western Lake Superior tributaries. Canadian Journal of Fisheries and Aquatic Sciences 62: 1254-1270.

Brown, J.H. \& Lomolino, M.V. 1998. Biogeography. Sunderland, Mass: Sinauer Associates.

Bussing, W.A. 1976. Geographic distribution of the San Juan ichthyofauna of Central America with remarks on its origin and ecology. In: Thorson, T.B., ed. Investigations of the ichthyofauna of Nicaraguan lakes. Lincoln, Nebraska: University of Nebraska, pp. 157-175.

Bussing, W.A. 1998. Peces de las aguas continentales de Costa Rica. Revista de Biología Tropical 46: 1-459.

Bussing, W.A. \& Lopez, M.I. 1977. Distribución y aspectos ecológicos de los peces de las cuencas hidrográficas de Arenal Bebederoy Tempisque, Costa Rica. Revista de Biologia Tropical 25: 13-37.

Dunham, J.B. \& Rieman, B.E. 1999. Metapopulation structure of bull trout: influences of physical, biotic, and geometrical landscape characteristics. Ecological Applications 9: 642655.

Durance, I., Lepichon, C. \& Ormerod, S.J. 2006. Recognizing the importance of scale in the ecology and management of riverine fish. River Research and Applications 22: 11431152.

Esselman, P.C. \& Boles, E. 2001. Status and future needs of limnological research in Belize. In: Wetzel, R.G. \& Gopal, B., eds. Limnology in developing countries, Volume 3. New Delhi, India: International Association of Limnology, pp. 3568

Esselman, P.C., Freeman, M.C. \& Pringle, C.M. 2006. Fishassemblage variation between geologically defined regions and across a longitudinal gradient in the Monkey River
Basin, Belize. Journal of the North American Benthological Society 25 : $142-156$.

Fausch, K.D., Torgersen, C.E., Baxter, C.V. \& Li, H.W. 2002. Landscapes to riverscapes: bridging the gap between research and conservation of stream fishes. BioScience 52: 483-498.

Frissell, C.A., Liss, W.J., Warren, C.E. \& Hurley, M.D. 1986. A hierarchical framework for stream habitat classification: viewing streams in a watershed context. Environmental Management 10: 199-214.

Gorman, O.T. \& Karr, J.R. 1978. Habitat structure and stream fish communities. Ecology 59: 507-515.

Greenfield, D.W. \& Thomerson, J.E. 1997. Fishes of the continental waters of Belize. Gainseville, FL: University of Florida Press.

Hartshorn, G., Nicolait, L., Hartshorn, L., Bevier, G., Brightman, R., Cal, J., Cawich, A., Davidson, W., DuBois, R., Dyer, C., Gibson, J., Hawley, W., Leonard, J., Nicolait, R., Weyer, D., White, H., \& Wright, C. 1984. Belize country environmental profile: a field study. Belize City, Belize: USAID.

Horowitz, R. 1978. Temporal variability patterns and the distributional patterns of stream fishes. Ecological Monographs 48: 307-321.

Johnson, R.K., Furse, M.T., Hering, D. \& Sandin, L. 2007. Ecological relationships between stream communities and spatial scale: implications for designing catchment-level monitoring programmes. Freshwater Biology 52: 939-958.

Lake, P.S., Bond, N. \& Reich, P. 2007. Linking ecological theory with stream restoration. Freshwater Biology 52: 597615.

Lammert, M. \& Allan, J.D. 1999. Assessing biotic integrity of streams: effects of scale in measuring the influence of land use/cover and habitat structure on fish and macroinvertebrates. Environmental Management 23: 257-270.

Lazorchak, J.M., Klemm, D.L. \& Peck, D.V., eds. 1998. Environmental Monitoring and Assessment Program Surfacewaters: Field operations and methods for measuring the ecological condition of Wadeable streams. Washington, D.C.: Office of Research and Development, U.S. Environmental Protection Agency.

Lee, M.D., Stednick, J.D. \& Gilbert, D.M. 1995. Belize environmental water quality monitoring: final report. Belmopan, Belize: USAID-NARMAP Project to Government of Belize.

Legendre, P. 1990. Quantitative methods and biogeographic analysis. In: Garbary, D.J. \& South, R.R., eds. Evolutionary biogeography of the marine algae of the North Atlantic. NATO ASI Series, Volume G 22. Berlin: Springer-Verlag, pp. 9-34.

Lyons, J. 1996. Patterns in the species composition of fish assemblages among Wisconsin streams. Environmental Biology of Fishes 45: 329-341.

Lyons, J. \& Schneider, D.W. 1990. Factors influencing fish distribution and community structure in a small coastal river in southwestern Costa Rica. Hydrobiologia 203: 1-14.

Matthews, W. 1998. Patterns in freshwater fish ecology. Norwell, MA: Chapman \& Hall.

Miller, R.R. 1966. Geographical distribution of Central American freshwater fishes. Copeia 1966: 773-802.

Ornelas-García, C.P., Domínguez-Domínguez, O. \& Doadrio, I. 2008. Evolutionary history of the fish genus Astyanax 


\section{Esselman \& Allan}

Baird \& Girard (1854) (Actinopterygii, Characidae) in Mesoamerica reveals multiple morphological homoplasies. BMC Evolutionary Biology 8: 340.

Poff, N.L. 1997. Landscape filters and species traits: towards mechanistic understanding and prediction in stream ecology. Journal of the North American Benthological Society 16: 391-409.

Rodiles-Hernandez, R., Diaz-Pardo, E. \& Lyons, J. 1999. Patterns in the species diversity and composition of the fish community of the Lacanja River, Chiapas, Mexico. Journal of Freshwater Ecology 14: 455-468.

Roth, N.E., Allan, J.D. \& Erickson, D.L. 1996. Landscape influences on stream biotic integrity assessed at multiple spatial scales. Landscape Ecology 11: 141-156.

Schlosser, I.J. 1982. Fish community structure and function along two habitat gradients in a headwater stream. Ecological Monographs 52: 395-414.

Schluter, D. \& Ricklefs, R. 1993. Convergence and the regional component of species diversity. In: Ricklefs, R. \& Schluter, D., eds. Species diversity in ecological communities. Chicago: University of Chicago Press, pp. 230-240.

Schmitter-Soto, J.J. 1998. Catalogo de los peces continentales de Quintana Roo. San Cristobal de las Casas, Mexico: El Colegio de la Frontera Sur.

Schmitter-Soto, J.J. \& Gamboa-Perez, H.C. 1996. Composición y distribución de peces continentales en el sur de Quintana Roo, Península de Yucatán, México. Revista de Biologia Tropical 44: 199-212.

Statzner, B., Gore, J.A. \& Resh, V.H. 1988. Hydraulic stream ecology: observed patterns and potential applications. Journal of the North American Benthological Society 7: 307-360.
Stewart-Koster, B., Kennard, M.J., Harch, B.D., Sheldon, F., Arthington, A.H. \& Pusey, B.J. 2007. Partitioning the variation in stream fish assemblages within a spatiotemporal hierarchy. Marine and Freshwater Research 58: 675-686.

Townsend, C.R. 1996. Concepts in river ecology: pattern and process in the catchment hierarchy. Archive fur Hydrobiologie 113(Suppl.): 3-21.

Wang, L.Z., Lyons, J., Rasmussen, P., Seelbach, P., Simon, T., Wiley, M., Kanehl, P., Baker, E., Niemela, S. \& Stewart, P.M. 2003. Watershed, reach, and riparian influences on stream fish assemblages in the Northern Lakes and Forest Ecoregion, USA. Canadian Journal of Fisheries and Aquatic Sciences 60: 491-505.

Wiens, J.A. 2002. Riverine landscapes: taking landscape ecology into the water. Freshwater Biology 47: 501-515.

Wiley, M., Kohler, S. \& Seelbach, P. 1997. Reconciling landscape and local views of aquatic communities: lessons from Michigan trout streams. Freshwater Biology 37: 133148.

Wilson, E.M. 1980. Physical geography of the Yucatan Peninsula. In: Moseley, E.H. \& Terry, E.D., eds. Yucatan: a world apart. Alabama: University of Alabama Press, pp. 540.

Winemiller, K.O. 1983. An introduction to the freshwater fish communities of Corcovado National Park, Costa Rica. Brenesia 21: 47-66.

Winemiller, K.O. \& Leslie, M.A. 1992. Fish assemblages across a complex, tropical freshwater marine ecotone. Environmental Biology of Fishes 34: 29-50. 